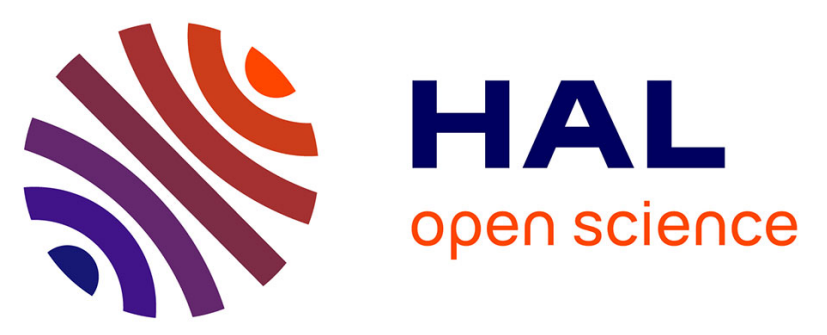

\title{
Development and evaluation of a new methodology for the fast generation of patient-specific Finite Element models of the buttock for sitting-acquired deep tissue injury prevention
}

\author{
Aurélien Macron, Hélène Pillet, Jennifer Doridam, Alexandre Verney, \\ Pierre-Yves Rohan
}

\section{To cite this version:}

Aurélien Macron, Hélène Pillet, Jennifer Doridam, Alexandre Verney, Pierre-Yves Rohan. Development and evaluation of a new methodology for the fast generation of patient-specific Finite Element models of the buttock for sitting-acquired deep tissue injury prevention. Journal of Biomechanics, 2018, 79, pp.173-180. 10.1016/j.jbiomech.2018.08.001 . hal-02305719

HAL Id: hal-02305719

https://hal.science/hal-02305719

Submitted on 4 Oct 2019

HAL is a multi-disciplinary open access archive for the deposit and dissemination of scientific research documents, whether they are published or not. The documents may come from teaching and research institutions in France or abroad, or from public or private research centers.
L'archive ouverte pluridisciplinaire HAL, est destinée au dépôt et à la diffusion de documents scientifiques de niveau recherche, publiés ou non, émanant des établissements d'enseignement et de recherche français ou étrangers, des laboratoires publics ou privés. 


\title{
Development and evaluation of a new methodology for the fast generation of patient-specific Finite Element models of the buttock for sitting-acquired deep tissue injury prevention
}

\author{
Aurélien Macron $^{\mathrm{a}, \mathrm{c}, *}$, Hélène Pillet ${ }^{\mathrm{a}}$, Jennifer Doridam ${ }^{\mathrm{a}}$, Alexandre Verney ${ }^{\mathrm{b}}$, Pierre-Yves Rohan ${ }^{\mathrm{a}}$ \\ ${ }^{a}$ Institut de Biomécanique Humaine Georges Charpak, Arts et Métiers ParisTech, 151 bd de l'Hôpital, 75013 Paris, France \\ ${ }^{\mathrm{b}}$ CEA, LIST, Interactive Robotics Laboratory, F-91191 Gif-sur-Yvette, France \\ ${ }^{\mathrm{c}}$ Univ. Grenoble Alpes, CEA, LETI, CLINATEC, MINATEC Campus, 38000 Grenoble, France
}

Keywords:

FEM

Ulcer

Subject specific

Buttock

Biomechanics

\section{A B S T R A C T}

The occurrence and management of Pressure Ulcers remain a major issue for patients with reduced mobility and neurosensory loss despite significant improvement in the prevention methods. These inju-ries are caused by biological cascades leading from a given mechanical loading state in tissues to irreversible tissue damage. Estimating the internal mechanical conditions within loaded soft tissues has the potential of improving the management and prevention of PU. Several Finite Element models of the buttock have therefore been proposed based on either MRI or CT-Scan data. However, because of the limited availability of MRI or CT-Scan systems and of the long segmentation time, all studies in the literature include the data of only one individual. Yet the inter-individual variability can't be overlooked when dealing with patient specific estimation of internal tissue loading. As an alternative, this contribu-tion focuses on the combined use of low-dose biplanar X-ray images, B-mode ultrasound images and optical scanner acquisitions in a nonweight-bearing sitting posture for the fast generation of patient-specific FE models of the buttock. Model calibration was performed based on Ischial Tuberosity sagging. Model evaluation was performed by comparing the simulated contact pressure with experimental obser-vations on a population of 6 healthy subjects. Analysis of the models confirmed the high inter-individual variability of soft tissue response (maximum Green Lagrange shear strains of $213 \pm 101 \%$ in the muscle). This methodology opens the way for investigating inter-individual factors influencing the soft tissue response during sitting and for providing tools to assess PU risk.

\section{Introduction}

A Pressure Ulcer (PU) is defined in the international guidelines as a localized injury to the skin and/or underlying tissues, usually over a bony prominence, resulting from sustained pressure. In patients with reduced mobility and neurosensory loss, the development of PU, and especially Deep Tissue Injury (DTI), remains frequent, with a prevalence of $33 \%$ in the first year, and an incidence of $80 \%$ during the whole life (Garber et al., 2000; Krause and Broderick, 2004). In addition to individual suffering, the development of PU's leads to a prolonged hospital stay (Allman et al., 1999) and increased treatment costs (Dealey et al., 2012).

\footnotetext{
* Corresponding author at: LBM/Institut de Biomécanique Humaine Georges Charpak, Arts et Métiers ParisTech, 151 bd de l'Hôpital, 75013 Paris, France. E-mail address: aurelien.macron@ensam.eu (A. Macron).
}

Several studies have consistently demonstrated that at least three mechanisms are involved in the development of PUs: (1) mechanically induced capillary occlusion resulting in tissue ischemia (Loerakker et al., 2011; Stekelenburg et al., 2007) along with reperfusion injury (Jiang et al., 2011; Peirce et al., 2000) (2) Cell deformation which can lead to a loss of membrane integrity and ultimately affecting viability and remodelling capacity (Bouten et al., 2003; Gefen et al., 2008; Linder-Ganz et al., 2006; Loerakker et al., 2011) (3) Impaired interstitial and lymphatic flow (Gray et al., 2016; Kasuya et al., 2014). The resulting cell death would impede any remodelling processes and lead to the accumulation of soft tissue breakdown. It has also been reported that such a situation can be exacerbated in the presence of elevated temperatures and moisture levels (Gefen, 2011; Sae-Sia et al., 2005). Most probably, the onset of damage development is multifactorial in nature and requires the contribution of several of these factors. 
In the last decades, growing resources have been invested into the development and implementation of evidence-based prevention protocols such as pressure relief strategies with patient mobilization and specific pressure-relieving cushions (Brem and Lyder, 2004). Despite these, PU incidence rates remain unacceptably high. As pointed out in (Gefen, 2009) the injury criteria, risk assessments or other clinical guidelines based on the (Reswick and Rogers, 1976) study fail to completely eliminate the risk of PU development. Indeed, many studies have established that the external pressure doesn't directly predict the mechanical response of the internal soft tissues (Chow and Odell, 1978; Dabnichki et al., 1994; Luboz et al., 2014; Oomens et al., 2003).

Based on the rationale that estimating the internal mechanical conditions within loaded soft tissues has the potential of improving the management and prevention of PU, several two-dimensional (Levy et al., 2013, 2014, Linder-Ganz et al., 2007, 2008, 2009; Sopher et al., 2010) and three-dimensional Finite Element (FE) models of the buttock (Al-Dirini et al., 2016; Levy et al., 2017; Levy and Gefen, 2017; Luboz et al., 2017; Moerman et al., 2017; Zeevi et al., 2017a) have been proposed based on either MRI (most of the studies) or CT-Scan data (Luboz et al., 2017). These studies have considerably advanced the analysis and understanding of the potential internal risks of the seated individual, and provided tools to assess PU risk based upon anatomy (Gefen, 2011; Levy et al., 2014; Luboz et al., 2017; Oomens et al., 2013; Zeevi et al., 2017b).

Yet, in all these studies, only 4 different tissue types are considered for FE modelling: bone, muscle tissue, fat tissue and skin. In the particular case of MRI data, although muscle groups, tendon, fat pads and ligament borders are visible, theses tissues are always modelled as one homogenous material to allow for convergence of tissue geometry. This approach, although computationally efficient, fails to take advantage of the capacity of MRI to differentiate between the individual soft tissue structures. As far as the authors are aware of, only the study reported by (Al-Dirini et al., 2016) differentiated 7 different muscle groups. However, the different interfaces were tied in the simulation phase limiting the benefit of accurately representing the internal tissue geometry. In addition, the representation of a realistic unloaded sitting position is jeopardized by the experimental limitations of MRIs and CT-scans: Long acquisition times of MR imaging prevent a prolonged unloaded sitting configuration without resorting to devices such as: rubber tires (Linder-Ganz et al., 2007), inclined plane (Al-Dirini et al., 2016) and thigh and arms supports (Call et al., 2017) while the confinement of the scanner limits the acquisition to the lying position only (Luboz et al., 2014).

Because of the limited availability of MRI or CT-Scan systems and of the long segmentation time associated with the creation of full 3D subject specific FE models from these imaging systems, all the studies in the literature included the data of only one individual (Al-Dirini et al., 2016; Luboz et al., 2014; Makhsous et al., 2007). Yet the inter-individual variability can't be overlooked when dealing with patient specific estimation of internal tissue loading which is obviously directly linked to the morphology of the bones. As far as the authors are aware of, the only attempts to account for this variability were limited to (i) semi-3D modelling ( $N=6$ able-bodied volunteers in (Linder-Ganz et al., 2007); $\mathrm{N}=12$ in (Linder-Ganz et al., 2008) including 6 able-bodied and 6 SCI volunteers; and $\mathrm{N}=6$ in (Linder-Ganz et al., 2009) including 3 able-bodied and $3 \mathrm{SCI}$ volunteers) and (ii) one attempt at 3D modelling ( $\mathrm{N}=6$ in (Moerman et al., 2017) including 3 ablebodied and $3 \mathrm{SCI}$ volunteers).

As an alternative to MRI-based/CT-scan-based assessment, this contribution focuses on the combined use of low-dose biplanar Xray images, B-mode ultrasound images and optical scanner acquisitions in a non-weight-bearing sitting posture for the fast generation of patient-specific FE models of the buttock. Model calibration was performed based on Ischial Tuberosity sagging. Model evaluation was performed by comparing the simulated contact pressure with experimental observations on a population of 6 healthy subjects.

\section{Materials and methods}

\subsection{Participants and protocol}

Six healthy subjects ( 5 men and 1 woman) participated in the study (Age: $28 \pm 4$ yrs, weight: $74 \pm 11 \mathrm{~kg}$, BMI: $22.7 \pm 1.7 \mathrm{~kg} / \mathrm{m}^{2}$ ). Exclusion criteria were: pregnancy and exposure to radiography in the last 6 months.

A custom-made stool with armrests was specifically designed for the experiment. A notch was made to fix the ultrasound probe at the level of the seat (Fig. 1c). Before each experiment, the stool was covered with a $2 \mathrm{~mm}$ thin removable plate and a pressure mattress $(59 \times 59 \mathrm{~cm}$ textile matrix of $32 \times 32$ sensors; spatial resolution $14.7 \mathrm{~mm}$, accuracy $\pm 10 \%$; range from 0.3 to $45 \mathrm{kPa}$; "TexiLat", "TexiMat", TexiSense) and placed in the EOS cabin. To determine the position of the pressure sensors in the EOS coordinate system, three markers were placed on the mattress. From an EOS acquisition, it was possible to obtain their 3D coordinates in the EOS reference frame $\left(R_{E O S}\right)$. In the same time, by manually pressing each marker, their coordinates was also expressed in the TexiMat reference frame $\left(R_{T E X I}\right)$. Then, the position of $R_{T E X I}$ with respect to $R_{E O S}$ could be inferred.

After approval by the ethics committee (Comité de protection des Personnes CPP NX06036) and written informed consent, the participants were equipped with 3 reflective markers: two on the posterior iliac spines of the pelvis and one on the spinal process of the 4th lumbar vertebra.

First, bi-planar X-ray radiographies $\left(\mathrm{EOS}^{\circledR}\right)$ were acquired in three configurations for each subject: (i) standardized free standing position (Faro et al., 2004), (ii) unloaded sitting by supporting their weight with their arms on the armrests (Fig. 1a), (iii) loaded sitting after translating their buttock with as small as possible rotation of their pelvis.

Second, the external shape of the buttock was scanned with a HandiScan (EinScan-ProTM; Shining 3D ${ }^{\circledR}$ ). Subjects were upright with one foot placed on a seat to reproduce the unloaded sitting position (Fig. 1b). The angle between the thigh and the trunk was measured and compared to the one measured during the EOS acquisition. Only half of the buttock region was scanned.

Third, an ultrasound acquisition of the subdermal tissue in the region beneath the ischial tuberosity was performed using a commercial device (Aixplorer, SuperSonic Imagine, France) with a linear ultrasound probe of $8 \mathrm{MHz}$ central frequency (SuperLinear SL 15-4). Before the acquisition, the cover of the stool was removed and the ultrasound probe fixed under the stool. The subject was asked to sit on the stool in front of the on-screen display of the ultrasound device. He was instructed to align his left ischium above the probe, to adjust his position to see the bone at the center of the screen and then to slowly unload his weight with his arms while visually keeping the ischium as aligned as possible with the probe. One ultrasound image was then acquired with the buttock unloaded in contact with the stool (Fig. 1c).

Finally, subjects were asked to sit on the stool positioned on a force plate with their feet outside the force plate. The total force applied to the stool by the subject when seated was measured.

\subsection{Patient specific geometry generation}

\subsubsection{Pelvis geometry}

$3 \mathrm{D}$ reconstruction of the pelvis was performed from the EOS radiographs in the standing position by a fully trained clinician 


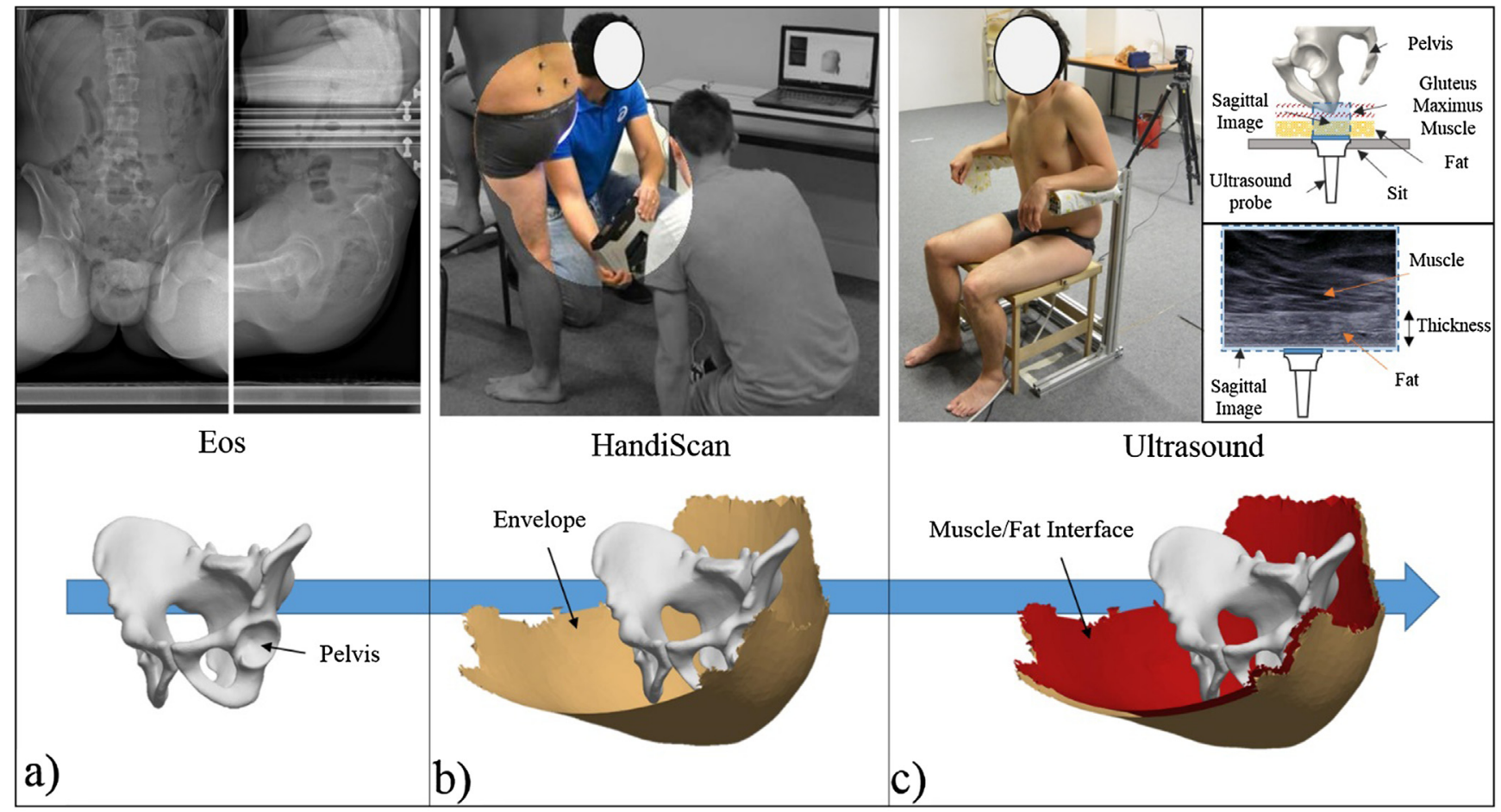

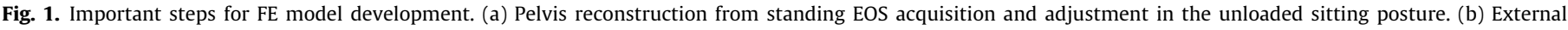

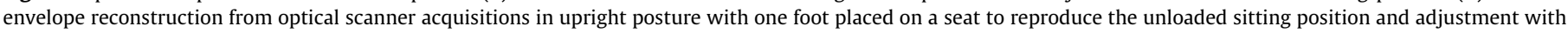
the pelvis by using external markers. (c) Measure of the thickness of the adipose layer and construction of the interface muscle/fat.

according to the procedure developed previously by (Mitton et al., 2006). The 3D subject-specific model of the pelvis was then projected on the frontal and sagittal radiographs in the unloaded sitting position. The position of the pelvis was manually adjusted until the contours matched those of the radiographs. The same procedure was repeated for the loaded sitting position.

\subsubsection{External envelope geometry}

The model given by the Handiscan was cleaned using Geomagic (Geomagic Inc., Research Triangle Park, NC). The two posterior pelvis markers were extracted and a sagittal plane was constructed normal to the medio-lateral direction defined by the markers and passing through the midpoint. A symmetry of the complete 3D model with respect to this plane was performed to generate the external envelope of the buttock.

\subsubsection{Fat and muscle layers}

The thickness of the adipose tissue was measured in the unloaded configuration on the ultrasound images. The interface between muscle and fat was obtained by applying this thickness as an offset to the external envelope. Finally, both 3D surfaces (envelope and interface) were semi-manually closed using Geomagic software.

\subsubsection{Registration by external markers}

To merge all the elements, a registration between both environments (Handiscan and EOS) was made through a technical frame, built from the coordinates of the three external markers (posterior iliac spines and lumbar spine process). The projection of the surface of the external envelope on the unloaded sitting radiographs was used to manually adjust its relative position by matching the contours of the model with the contours of radiographic image of the envelope.

\subsection{Finite Element modeling}

\subsubsection{Finite Element mesh}

The geometry defined in the unloaded configuration was imported in ABAQUS FEA software (ABAQUS 6.12-3. DS Simulia, Providence, RI). From Boolean operations, two deformable solids were constructed: the adipose tissue by removing the volume $V_{p f}$ bounded by the fat/muscle interface to the volume of the envelope and the muscle by removing the pelvis to the volume $V_{p f}$. A skin shell layer was also defined with the envelope surface with a thickness of $1 \mathrm{~mm}$ (Moerman et al., 2016). A rigid horizontal plane was created at the lowest node of the envelope to model the seat.

The meshing tools available in ABAQUS ${ }^{\circledR}$ were used to generate the computational mesh. Linear tetrahedral elements with hybrid formulation $(\mathrm{C} 3 \mathrm{D} 4 \mathrm{H})$ were used. The models contained about 320000 elements and 215000 degrees of freedom (including the Lagrange Multiplier variables). The pelvis was assumed to be rigid and meshed with linear triangle shell elements. A mesh convergence test was performed showing that further mesh refinement produced a negligible change in the solution (maximum shear strain).

2.3.2. Constitutive equations and calibration of the material properties

The skin, fat and muscle tissues were each modelled with a first order Ogden Hyper-Elastic material model (Simo and Taylor, 1991) with the following Strain Energy Density formulation:

$\Psi=2 * \frac{\mu}{\alpha^{2}} *\left(\bar{\lambda}_{1}^{-\alpha}+\bar{\lambda}_{2}^{-\alpha}+\bar{\lambda}_{3}^{-\alpha}-3\right)+\frac{1}{D} *(J-1)^{2}$

where $\bar{\lambda}_{i}$ are the deviatoric principal stretches $\left(\bar{\lambda}_{i}=J^{-\frac{1}{3}} \cdot \lambda_{i}\right)$ J is related to the third invariant of the right Cauchy-Green tensor and, $\mu[\mathrm{kPa}], \alpha[-]$ and $D\left[\mathrm{kPa}^{-1}\right]$ the material properties (respectively the shear modulus, the exponent and $\mathrm{D}$ the material incompressibility parameter defined based on the bulk modulus $k$ as 
$\left.D=\frac{2}{k}\right)$. Soft tissues were assumed to be nearly incompressible. The Poisson's ratios were therefore fixed to 0.49 and material incompressibility parameter $D$ was approximated as follows (Mott et al., 2008):

$D=\frac{2}{\kappa} \approx \frac{3(1-2 v)}{\mu(1+v)}$

Material parameters for the skin were fixed to $\mu=20 \mathrm{kPa}$ and $\alpha=5$ respectively based on values reported in the literature (Luboz et al., 2014). For the fat and the muscle, $\alpha$ was fixed to 5 (Luboz et al., 2014) and the shear modulus $\mu$ was calibrated using Finite Element Updating to fit the experimental Ischial tuberosity sagging. This was computed as the mean value of the vertical displacements $\Delta=d_{1}-d_{2}$ (Fig. 2) of the right and left ischial tuberosity between the unloaded sitting $d_{1}$ and the loaded sitting $d_{2}$ EOS positions.

The resolution was performed via an implicit scheme. The default convergence criteria in ABAQUS/Standard were used.

\subsubsection{Boundary conditions}

For the boundary conditions, all the degrees of freedom (DOF) of the pelvis were fixed except for the vertical displacement. A vertical force equal to the one measured when seated on the stool was applied at the center of mass of the pelvis. The nodes at the different interfaces (bone/muscle, muscle/fat, and fat/skin) of the model were tied. A friction contact was defined between the rigid plane and the skin surface using a penalty algorithm. The friction coefficient was set to 0.4 (Al-Dirini et al., 2016).

\subsubsection{Post-processing}

To compare to the literature, (i) the principal Green Lagrange strains were calculated as $E_{i}=\frac{\lambda_{i}^{2}-1}{2}$ from the principal stretches $\lambda_{i}$ ( $i=I$, II or III) with $E_{I I I}$ the maximum compressive strain and (ii) the maximum shear strains were then determined as $E_{\max }=\frac{1}{2} * \max \left(\left|E_{I}-E_{I I}\right|,\left|E_{I I}-E_{I I I}\right|,\left|E_{I I I}-E_{I}\right|\right)$.
In line with (Bucki et al., 2016; Luboz et al., 2017) a "cluster analysis" was performed to investigate volumes of the model that are in certain intervals of maximum shear strain. Clusters were defined as adjacent elements with a maximum shear strain and a maximum compressive strain above $75 \%$ and $45 \%$ respectively (damage thresholds reported by Ceelen et al. (2008b)). Muscle and fat were differentiated. The maximum, the mean and the standard deviation of $E_{I I I}$ and $E_{\max }$ in the largest cluster were calculated. Elements in the sacral region were discarded to focus only on the ischium region.

\subsection{Model evaluation}

Model evaluation was performed by comparing the simulated contact pressure with the distribution of the external pressure measured by the mattress in $R_{E O S}$. The contact stress distributions predicted by the model were interpolated onto a grid of the same resolution as the one of the pressure mattress and an optimization of the relative position of the experimental sensors and the numerical grid was performed to minimize the mean error between both distributions. The numerical and experimental contact pressure distributions were then post processed to generate area engagement histograms, corresponding to the fractional areas of the buttock interface experiencing specific ranges of contact stress and compared. Each data point represents the high point of that range of contact stress values.

\section{Results}

\subsection{Calibration values}

The FE model was calibrated against the experimental values of the Ischial tuberosity sagging measured on the sagittal view of the EOS acquisitions. Both the sagging values and the identified material parameters $(\mu, \alpha)$ of the muscle and fat layers obtained after FE model calibration are reported in Table 1 below for each subject.

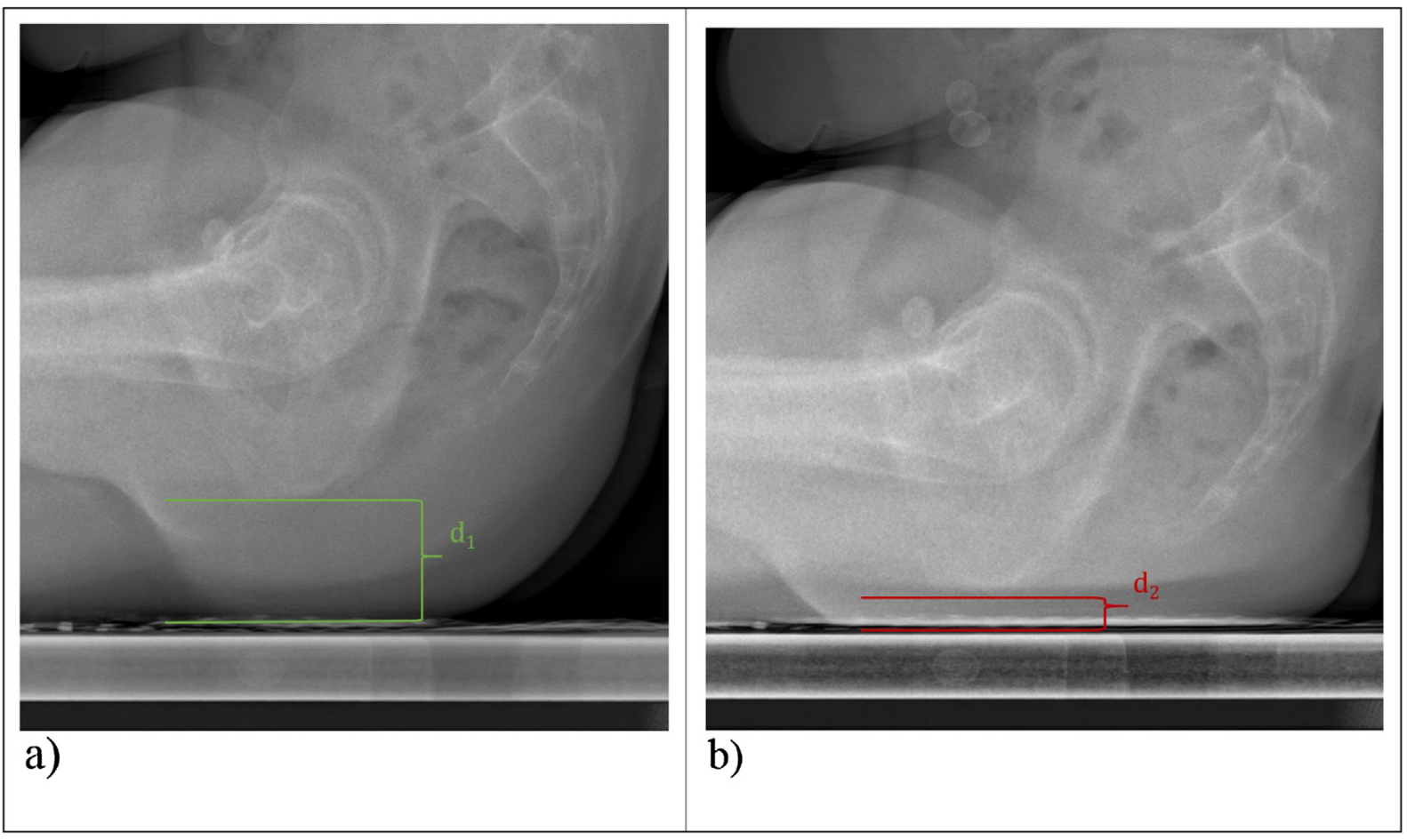

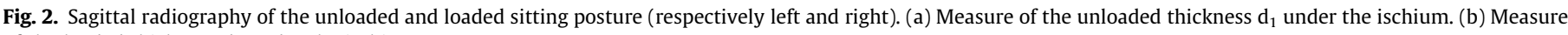
of the loaded thickness $d_{2}$ under the ischium. 
Table 1

Experimental values of sagging and mechanical properties of the adipose tissue and muscle obtained after FE model calibration.

\begin{tabular}{|c|c|c|c|c|c|c|}
\hline Parameters & Subject \#1 & Subject \#2 & Subject \#3 & Subject \#4 & Subject \#5 & Subject \#6 \\
\hline Experimental values of the pelvis sagging $(\mathrm{mm})$ & 28 & 40 & 31 & 33 & 36 & 40 \\
\hline \multicolumn{7}{|l|}{ Material properties $\mu[\mathrm{kPa}]\left(\alpha\left[\_\right]\right)$} \\
\hline Muscle & $8.00(5)$ & $4.80(8)$ & $4.80(8)$ & $6.25(5)$ & $6.25(5)$ & $1.00(5)$ \\
\hline Adipose & $5.00(5)$ & $3.75(5)$ & $4.25(5)$ & $3.75(5)$ & $3.75(5)$ & $4.5(8)$ \\
\hline
\end{tabular}

\subsection{Model evaluation}

The two peaks of pressure, right and left, of the experimental distributions were saturated at $45 \mathrm{kPa}$, except for the subject 2 . The mean difference of pressure was below $1 \mathrm{kPa}$, showing good agreement between the experiments and FE models. The measured versus computed distributions of contact areas across the contact stress plots showed substantial agreement between the experiments and FE models (Fig. 4).

\subsection{Mechanical response of the subdermal soft tissues}

Table 2 below summarizes the cluster volumes with the associated shear and compressive strains endured by the muscle and the fat tissue for each subject. The biggest clusters are in the muscle tissue except for the subject 2, however there are always under the ischium (Fig. 3). For the muscle, the subject 6 has the maximum cluster volume $\left(34.1 \mathrm{~cm}^{3}\right)$ with the highest mean shear strains and compressive strains, respectively $164 \%$ and $-47.4 \%$. For the other subjects, the mean shear strain endured by the maximum cluster are similar $(136 \pm 7 \%)$ unlike the maximum shear strain $(173 \pm 21 \%)$. For the fat tissue, the subject 1 has no volume of tissue above the threshold defined by Ceelen et al. (2008b). The maximum and the mean shear strain endured by the cluster are similar among the subjects (respectively $156 \pm 10 \%$ and $136 \pm 9 \%$ ).

\subsection{Length of time to model}

The acquisition and the generation of the subject specific FE model last approximately $5 \mathrm{~h}$ for each subject.

\section{Discussion}

Generation of subject-specific FE models for the assessment of the subject-specific in vivo sub-dermal soft tissue strains and stresses in the ischial regions during sitting remains a challenging bottleneck today because they are traditionally generated from MR images or CT scan data which require intensive user intervention at multiple stages of the segmentation process. The aim of this study was to develop and to evaluate, on a population of 6 subjects, a new methodology for the fast generation of 3D FE model of the buttock for sitting-acquired Deep Tissue Injury prevention using a combination of low-dose biplanar X-ray images, B-mode ultrasound images and optical scanner acquisitions. Ischial tuberosity sagging between the non-weight-bearing and weight-bearing sitting positions respectively was used for model calibration and external interface pressure measurements for model evaluation.

All the subjects had clusters of muscle tissue enduring compressive and maximal shear strain above the thresholds defined in the literature (Ceelen et al., 2008a; Loerakker et al., 2011). In agreement with previous results reported in the literature (LinderGanz et al., 2007), our results showed that the maximal tissue strains and stresses occurred in the muscle layer at the bone interface. Likewise our results confirm the high inter-individual variability with a mean maximal shear strain of $213 \pm 100 \%$ in the muscle. The important difference in strain response between the subject 6 and the other subjects could be explained by the low shear modulus identified. The lack of constraints in the proposed objective function for calibration (i.e. based on sagging only) could possibly result in a multiple solutions for each subject. This constitutes one limit of the current calibration method employed. It is envisaged to improve the individualisation of the material properties in future studies by exploring the possibility of using either (i) Shear wave Elastography measurements and/or (ii) Ultrasound Indentation measurements (based on (Makhsous et al., 2008)).

Recently, clinical studies focusing on in vivo buttock deformation quantification using MR imaging called into question the assumption that deep tissue injuries originates in the soft tissues adjacent to a bony prominence where highest strains are located. (Sonenblum et al., 2015) used 3D seated MRI to describe the anatomy and deformation of the buttocks for 4 able-bodied and $3 \mathrm{SCI}$ subjects during sitting in loaded and unloaded conditions. The authors showed that, in the loaded configuration, 5 subjects out of 7 only had fat tissue beneath the IT, the Gluteus Maximus (GM) being positioned more laterally and posteriorly to the IT. Likewise, (Call et al., 2017) observed, using MRI, that, in a population of 10 spinal cord injury subjects and one able-bodied person, no muscle were present beneath the IT for $40 \%$ of the SCI subjects

Table 2

Maximal components of the principal and shear strains (Cauchy) among the subjects.

\begin{tabular}{|c|c|c|c|c|c|c|c|c|}
\hline Threshold $E_{I I I}>45 \%$ and $E_{\max }>75 \%$ & Subject & & \#1 & \#2 & \#3 & $\# 4$ & \#5 & \#6 \\
\hline \multirow{7}{*}{ Muscle } & Max cluster volume $\left(\mathrm{cm}^{3}\right)$ & & 1.2 & 2.7 & 3.6 & 1.5 & 4.7 & 34.1 \\
\hline & Third principal strain $E_{I I I}(\%)$ & Maximum & -47.5 & -48.9 & -49.1 & -49.0 & -49.1 & -49.9 \\
\hline & & Mean & -46.0 & -46.9 & -47.0 & -46.1 & -46.3 & -47.4 \\
\hline & & Standard Deviation & 0.8 & 1.0 & 1.1 & 1.0 & 1.0 & 1.5 \\
\hline & Maximum shear strain $E_{\max }(\%)$ & Maximum & 142 & 176 & 187 & 158 & 202 & 414 \\
\hline & & Mean & 127 & 136 & 137 & 132 & 146 & 164 \\
\hline & & Standard Deviation & 11 & 24 & 24 & 15 & 20 & 48 \\
\hline \multirow[t]{7}{*}{ Fat } & Max cluster volume $\left(\mathrm{cm}^{3}\right)$ & & 0 & 6.7 & 1.9 & 1.1 & 2.3 & 2.5 \\
\hline & Third principal strain $E_{I I I}(\%)$ & Maximum & - & -47.7 & -47.4 & -46.4 & -48.1 & -47.7 \\
\hline & & Mean & - & -46.0 & -46.2 & -45.4 & -46.4 & -46.1 \\
\hline & & Standard Deviation & - & 0.9 & 1.0 & 0.5 & 0.8 & 0.7 \\
\hline & Maximum shear strain $E_{\max }(\%)$ & Maximum & - & 143 & 157 & 152 & 173 & 153 \\
\hline & & Mean & - & 123 & 140 & 128 & 146 & 142 \\
\hline & & Standard Deviation & - & 12 & 13 & 12 & 17 & 9 \\
\hline
\end{tabular}




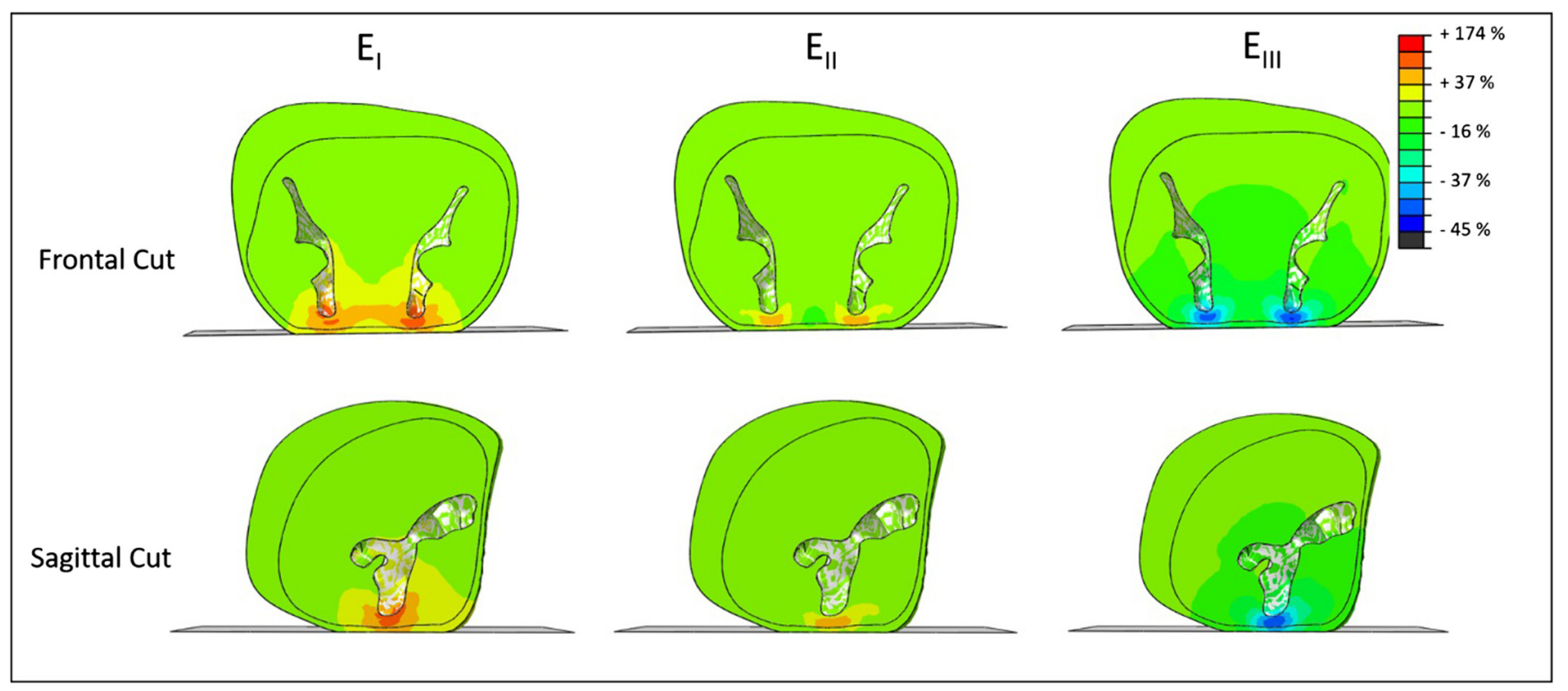

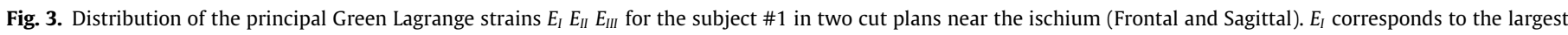

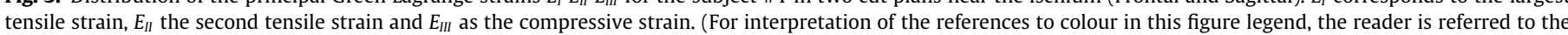
web version of this article.)

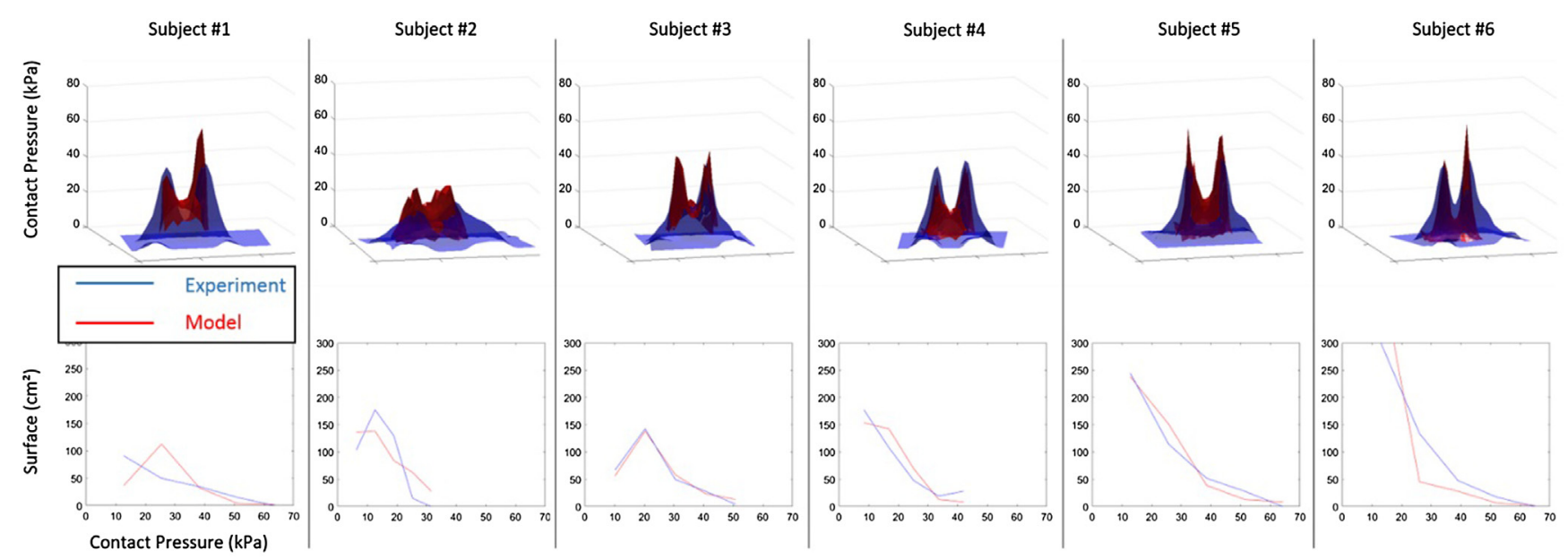

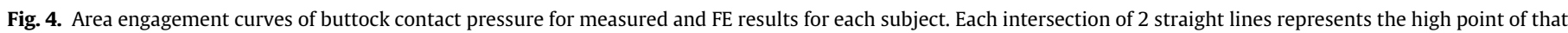
range of contact pressure values (e.g., the intersection at $20 \mathrm{kPa}$ reflects region with pressure under $20 \mathrm{kPa}$ and above the last intersection value).

during sitting. All the FE models reported in the literature however (including those modelling volunteers with SCI (Linder-Ganz et al., 2009; Moerman et al., 2017)) did not capture this behaviour. In agreement with the conclusion of (Al-Dirini et al., 2016) we deduce that this could partly be explained by the (simplified) tied/non-slip contact assigned to the bone-muscle-fat interfaces. Considering the current state of the art in this field of research, both simulation and experimental issues have to be addressed before considering individualizing the behaviour of subcutaneous tissues. Actually it is very well possible that DTI starts in subcutaneous fat in SCI patients in whom the muscle layer becomes fatty and completely disappears - leaving the Ischial Tuberosity resting on the adipose tissue only. Unfortunately, very little is known today regarding the damage mechanisms in fat: skeletal muscles being far more sensitive to compressive loading than fat and skin (Daniel et al., 1981; Nola and Vistnes, 1980), they have been the focus of the research work on tissue injury thresholds as related to PUs. Going forward more realistic representation of the behaviour of the different tissues in the buttock during loading should help improve the understanding of the onset of DTI and therefore would allow a better prevention.

In spite of this, interface contact pressure predicted by the model were in good agreement with the interface pressure measurements acquired with the TexiMat textile pressure sensor. On average, the mean and standard deviation of the point by point error were respectively $0.4 \mathrm{kPa}$ and $6.81 \mathrm{kPa}$. Furthermore, the measured and the computed contact areas for different ranges of contact stresses were close. The modest discrepancies for the subject 1 and 2 could be due to a change in the pelvis orientation between the unloaded and loaded state, these two subjects having more than $3^{\circ}$ rotation in the sagittal plane which can be enough to modify the pattern of the contact pressure. However the experiments were limited by the range of the pressure mattress, i.e values above $45 \mathrm{kPa}$, hindering an evaluation of the models through the peaks of pressure.

As far as the authors are aware of, if in vivo soft tissue strain levels have been reported in animal models using MR tagging (Ceelen et al., 2008b; Loerakker et al., 2010; Solis et al., 2012), no 
study has ever reported in vivo tissue strain in humans. In the literature, authors have only reported values for global deformation (i.e. ratio of the total tissue volume (or thickness) in the loaded configuration to the volume (or thickness) in the unloaded configuration (e.g in (Brienza et al., 2018)) which is not sufficient. As a result, in vivo tissue strain predicted by FE models in humans have never been validated against experimental data. One of the shortterm perspective is to take advantage of the B-mode ultrasound imaging used in the current protocol for the quantification of internal soft-tissue strains of buttock tissues during sitting in order to enhance the modelling of the transmission of loads into the different structures composing the buttock.

From a clinical perspective, the biological cascades leading from a given mechanical loading state in tissues to irreversible tissue damage are multidimensional, and include direct cellular damage, changes in transport and metabolism at the cell and tissue scales, ischemic factors, poor lymphatic function and possibly reperfusion injuries (Gray et al., 2016; Linder-Ganz et al., 2006; Loerakker et al., 2010; Oomens, 2013). In particular, estimating the internal mechanical conditions within loaded soft tissues has the potential of improving the management and prevention of PUs (Ceelen et al., 2008a; Gefen et al., 2008). As a future work, it would also be interesting and useful to extend the proposed protocol to people with reduced mobility. This would allow to obtain data on vulnerable populations and to have a quantitative estimation of sub-dermal soft tissue biomechanical response in new seat and cushion designs. This could also potentially have an impact on the design of exoskeletons such as EMY (Enhancing MobilitY) (Morinière et al., 2015) developed in the BCI project (Eliseyev et al., 2014) for disabled persons and where the mechanical interfaces are paramount. From that perspective, the combined use of calibrated biplanar X-ray imaging and B-mode Ultrasound imaging could potentially improve on the shortcomings with MRI/CT imaging in that (i) due to the relatively short time ( $5 \mathrm{~h}$ per subject) necessary to develop patient specific models, many subjects can easily be analysed providing valuable insight into inter-individual variability (ii) realistic unloaded / loaded sitting position can easily be acquired.

\section{Conflict of interest statement}

The authors certify that no conflict of interest is raised by this work.

\section{Acknowledgments}

This work was supported by the Fondation de l'Avenir (grant number AP-RM-2016-030), by la Fondation des Arts et métiers and the Fond de dotation Clinatec. The authors are also grateful to the ParisTech BiomecAM chair program on subject-specific musculoskeletal modelling.

\section{References}

Al-Dirini, R.M.A., Reed, M.P., Jingwen, H., Thewlis, D., 2016. Development and Validation of a High Anatomical Fidelity FE Model for the Buttock and Thigh of a Seated Individual 44, 2805-2816. https://doi.org/10.1007/s10439-016-1560-3.

Allman, R.M., Goode, P.S., Burst, N., Bartolucci, A.A., Thomas, D.R., 1999. Pressure ulcers, hospital complications, and disease severity: impact on hospital costs and length of stay. Adv. Wound Care J. Prev. Heal. 12, 22-30.

Bouten, C.V., Oomens, C.W., Baaijens, F.P., Bader, D.L., 2003. The etiology of pressure ulcers: skin deep or muscle bound? Arch. Phys. Med. Rehabil. 84, 616-619. https://doi.org/10.1053/apmr.2003.50038.

Brem, H., Lyder, C., 2004. Protocol for the successful treatment of pressure ulcers. Am. J. Surg. 188, 9-17. https://doi.org/10.1016/S0002-9610(03)00285-X.

Brienza, D., Vallely, J., Karg, P., Akins, J., Gefen, A., 2018. An MRI investigation of the effects of user anatomy and wheelchair cushion type on tissue deformation. J.
Tissue Viability Seating Biomech. 27, 42-53. https://doi.org/10.1016/j. jtv.2017.04.001.

Bucki, M., Luboz, V., Perrier, A., Champion, E., Diot, B., Vuillerme, N., Payan, Y., 2016. Clinical workflow for personalized foot pressure ulcer prevention. Med. Eng. Phys. 38, 845-853. https://doi.org/10.1016/j.medengphy.2016.04.017.

Call, E., Hetzel, T., McLean, C., Burton, J.N., Oberg, C., 2017. Off loading wheelchair cushion provides best case reduction in tissue deformation as indicated by MRI. J. Tissue Viability 26, 172-179. https://doi.org/10.1016/j.jtv.2017.05.002.

Ceelen, K.K., Stekelenburg, A., Loerakker, S., Strijkers, G.J., Bader, D.L., Nicolay, K. Baaijens, F.P.T., Oomens, C.W.J., 2008a. Compression-induced damage and internal tissue strains are related. J. Biomech. 41, 3399-3404. https://doi.org/ 10.1016/j.jbiomech.2008.09.016.

Ceelen, K.K., Stekelenburg, A., Mulders, J.L., Strijkers, G.J., Baaijens, F.P.T., Nicolay, K., Oomens, C.W.J., 2008b. Validation of a numerical model of skeletal muscle compression with MR tagging: a contribution to pressure ulcer research. J. Biomech. Eng. 130. https://doi.org/10.1115/1.2987877. 061015-061015-8.

Chow, W.W., Odell, E.I., 1978. Deformations and stresses in soft body tissues of a sitting person. J. Biomech. Eng. 100, 79-87. https://doi.org/10.1115/1.3426196.

Dabnichki, P.A., Crocombe, A.D., Hughes, S.C., 1994. Deformation and stress analysis of supported buttock contact. Proc. Inst. Mech. Eng. [H] 208, 9-17. https://doi. org/10.1177/095441199420800102.

Daniel, R.K., Priest, D.L., Wheatley, D.C., 1981. Etiologic factors in pressure sores: an experimental model. Arch. Phys. Med. Rehabil. 62, 492-498.

Dealey, C., Posnett, J., Walker, A., 2012. The cost of pressure ulcers in the United Kingdom. J. Wound Care 21, 261-266.

Eliseyev, A., Mestais, C., Charvet, G., Sauter, F., Abroug, N., Arizumi, N., Cokgungor, S, Costecalde, T., Foerster, M., Korczowski, L., Moriniere, B., Porcherot, J., Pradal, J., Ratel, D., Tarrin, N., Torres-Martinez, N., Verney, A., Aksenova, T., Benabid, A.-L., 2014. CLINATEC ${ }^{\circledR}$ BCI platform based on the ECoG-recording implant WIMAGINE $^{\circledR}$ and the innovative signal-processing: Preclinical results. In: 2014 36th Annual International Conference of the IEEE Engineering in Medicine and Biology Society. IEEE, pp. 1222-1225. https://doi.org/10.1109/ EMBC.2014.6943817.

Faro, F.D., Marks, M.C., Pawelek, J., Newton, P.O., 2004. Evaluation of a functional position for lateral radiograph acquisition in adolescent idiopathic scoliosis. Spine 29, 2284-2289.

Garber, S.L., Rintala, D.H., Hart, K.A., Fuhrer, M.J., 2000. Pressure ulcer risk in spinal cord injury: predictors of ulcer status over 3 years. Arch. Phys. Med. Rehabil. 81, 465-471. https://doi.org/10.1053/mr.2000.3889.

Gefen, A., 2011. How do microclimate factors affect the risk for superficial pressure ulcers: a mathematical modeling study. J. Tissue Viability 20, 81-88. https://doi. org/10.1016/j.jtv.2010.10.002.

Gefen, A., 2009. Reswick and Rogers pressure-time curve for pressure ulcer risk. Part 1. Nurs. Stand. R. Coll. Nurs. G. B. 1987 23, 64, 66, 68 passim. https://doi.org/10. 7748/ns2009.07.23.45.64.c7115.

Gefen, A., van Nierop, B., Bader, D.L., Oomens, C.W., 2008. Strain-time cell-death threshold for skeletal muscle in a tissue-engineered model system for deep tissue injury. J. Biomech. 41, 2003-2012. https://doi.org/10.1016/j. jbiomech.2008.03.039.

Gray, R.J., Voegeli, D., Bader, D.L., 2016. Features of lymphatic dysfunction in compressed skin tissues - implications in pressure ulcer aetiology. J. Tissue Viability 25, 26-31. https://doi.org/10.1016/j.jtv.2015.12.005.

Jiang, L., Tu, Q., Wang, Y., Zhang, E., 2011. Ischemia-reperfusion injury-induced histological changes affecting early stage pressure ulcer development in a rat model. Ostomy Wound Manage. 57, 55-60.

Kasuya, A., Sakabe, J., Tokura, Y., 2014. Potential application of in vivo imaging of impaired lymphatic duct to evaluate the severity of pressure ulcer in mouse model. Sci. Rep. 4. https://doi.org/10.1038/srep04173.

Krause, J.S., Broderick, L., 2004. Patterns of recurrent pressure ulcers after spinal cord injury: identification of risk and protective factors 5 or more years after onset11No commercial party having a direct financial interest in the results of the research supporting this article has or will confer a benefit upon the author (s) or upon any organization with which the author(s) is/are associated. Arch. Phys. Med. Rehabil. 85, 1257-1264. https://doi.org/10.1016/j. apmr.2003.08.108.

Levy, A., Gefen, A., 2017. Assessment of the biomechanical effects of prophylactic sacral dressings on tissue loads: a computational modeling analysis. Ostomy Wound Manage. 63, 48-55.

Levy, A., Kopplin, K., Gefen, A., 2014. An air-cell-based cushion for pressure ulcer protection remarkably reduces tissue stresses in the seated buttocks with respect to foams: finite element studies. J. Tissue Viability 23, 13-23. https:// doi.org/10.1016/j.jtv.2013.12.005.

Levy, A., Kopplin, K., Gefen, A., 2013. Simulations of skin and subcutaneous tissue loading in the buttocks while regaining weight-bearing after a push-up in wheelchair users. J. Mech. Behav. Biomed. Mater. 28, 436-447. https://doi.org/ 10.1016/j.jmbbm.2013.04.015.

Levy, A., Schwartz, D., Gefen, A., 2017. The contribution of a directional preference of stiffness to the efficacy of prophylactic sacral dressings in protecting healthy and diabetic tissues from pressure injury: computational modelling studies. Int. Wound J. 14, 1370-1377. https://doi.org/10.1111/iwj.12821.

Linder-Ganz, E., Engelberg, S., Scheinowitz, M., Gefen, A., 2006. Pressure-time cell death threshold for albino rat skeletal muscles as related to pressure sore biomechanics. J. Biomech. 39, 2725-2732. https://doi.org/10.1016/j. jbiomech.2005.08.010. 
Linder-Ganz, E., Shabshin, N., Itzchak, Y., Gefen, A., 2007. Assessment of mechanical conditions in sub-dermal tissues during sitting: a combined experimental-MRI and finite element approach. J. Biomech. 40, 1443-1454. https://doi.org/ 10.1016/j.jbiomech.2006.06.020.

Linder-Ganz, E, Shabshin, N., Itzchak, Y, Yizhar, Z, Siev-Ner, I, Gefen, A, 2008 Strains and stresses in sub-dermal tissues of the buttocks are greater in paraplegics than in healthy during sitting. J. Biomech. 41, 567-580. https://doi. org/10.1016/j.jbiomech.2007.10.011.

Linder-Ganz, E., Yarnitzky, G., Yizhar, Z., Siev-Ner, I., Gefen, A., 2009. Real-time finite element monitoring of sub-dermal tissue stresses in individuals with spinal cord injury: toward prevention of pressure ulcers. Ann. Biomed. Eng. 37, 387400. https://doi.org/10.1007/s10439-008-9607-8.

Loerakker, S., Manders, E., Strijkers, G.J., Nicolay, K., Baaijens, F.P.T., Bader, D.L., Oomens, C.W.J., 2011. The effects of deformation, ischemia, and reperfusion on the development of muscle damage during prolonged loading. J. Appl. Physiol. 111, 1168-1177. https://doi.org/10.1152/japplphysiol.00389.2011.

Loerakker, S., Stekelenburg, A., Strijkers, G.J., Rijpkema, J.J.M., Baaijens, F.P.T., Bader, D.L., Nicolay, K., Oomens, C.W.J., 2010. Temporal effects of mechanical loading on deformation-induced damage in skeletal muscle tissue. Ann. Biomed. Eng. 38, 2577-2587. https://doi.org/10.1007/s10439-010-0002-x.

Luboz, V., Bailet, M., Boichon, C., Rochette, M., Diot, B., Bucki, M., Payan, Y., 2017. Personalized modeling for real-time pressure ulcer prevention in sitting posture. J. Tissue Viability 2-6. https://doi.org/10.1016/j.jtv.2017.06.002.

Luboz, V., Petrizelli, M., Bucki, M., Diot, B., Vuillerme, N., Payan, Y., 2014. Biomechanical modeling to prevent ischial pressure ulcers. J. Biomech. 47, 2231-2236. https://doi.org/10.1016/j.jbiomech.2014.05.004p.

Makhsous, M., Lim, D., Hendrix, R., Bankard, J., Rymer, W.Z., Lin, F., 2007. Finite Element Analysis for Evaluation of Pressure Ulcer on the Buttock : Development and Validation 15, 517-525.

Makhsous, M., Venkatasubramanian, G. Chawla, A., Pathak, Y., Priebe, M., Rymer, W. Z., Lin, F., 2008. Investigation of Soft-Tissue Stiffness Alteration in Denervated Human Tissue Using an Ultrasound Indentation System. J. Spinal Cord Med. 31, 88-96.

Mitton, D., Deschênes, S., Laporte, S., Godbout, B., Bertrand, S., Guise, J.A. De, Skalli, W., 2006. Computer methods in biomechanics and biomedical engineering 3D reconstruction of the pelvis from bi-planar radiography 3D reconstruction of the pelvis from bi-planar radiography. Comput. Methods Biomech. Biomed. Eng. 9, 1-5. https://doi.org/10.1080/10255840500521786.

Moerman, K.M., van Vijven, M., Solis, L.R., van Haaften, E.E., Loenen, A.C.Y., Mushahwar, V.K., Oomens, C.W.J., 2017. On the importance of 3D, geometrically accurate, and subject-specific finite element analysis for evaluation of in-vivo soft tissue loads. Comput. Methods Biomech. Biomed. Eng. 20, 483-491. https://doi.org/10.1080/10255842.2016.1250259.

Moerman, K.M., Vijven, M. Van, Solis, LR, Haaften, E.E Van, Loenen, A.C.Y. Mushahwar, V.K., Oomens, C.W.J., Moerman, K.M., Vijven, M. Van, Solis, L.R. Haaften, E.E. Van, 2016. Engineering On the importance of 3D, geometrically accurate, and subject-specific finite element analysis for evaluation of in-vivo soft tissue loads. Comput. Methods Biomech. Biomed. Eng. 5842. https://doi. org/10.1080/10255842.2016.1250259.

Morinière, B., Verney, A., Abroug, N., Garrec, P., Perrot, Y., 2015. EMY: A dual arm exoskeleton dedicated to the evaluation of Brain Machine Interface in clinical trials. In: IEEE International Conference on Intelligent Robots and Systems. pp. 5333-5338. https://doi.org/10.1109/IROS.2015.7354130.
Mott, P.H., Dorgan, J.R., Roland, C.M., 2008. The bulk modulus and Poisson's ratio of "incompressible" materials. J. Sound Vib. 312, 572-575. https://doi.org/ 10.1016/j.jsv.2008.01.026

Nola, G.T., Vistnes, L.M., 1980. Differential response of skin and muscle in the experimental production of pressure sores. Plast. Reconstr. Surg. 66, 728-733.

Oomens, C.W.J., 2013. A multilevel finite element approach to study pressure ulcer aetiology. In: Multiscale Computer Modeling in Biomechanics and Biomedical Engineering, Studies in Mechanobiology, Tissue Engineering and Biomaterials. Springer, Berlin, Heidelberg, pp. 289-298. https://doi.org/10.1007/8415 2012158.

Oomens, C.W.J., Bressers, O.F.J.T., Bosboom, E.M.H., Bouten, C.V.C., Bader, D.L., 2003 Can loaded interface characteristics influence strain distributions in muscle adjacent to bony prominences ? Comput. Methods Biomech. Biomed. Eng. 6 171-180. https://doi.org/10.1080/1025584031000121034.

Oomens, C.W.J., Zenhorst, W., Broek, M., Hemmes, B., Poeze, M., Brink, P.R.G., Bader D.L., 2013. A numerical study to analyse the risk for pressure ulcer development on a spine board. Clin. Biomech. 28, 736-742. https://doi.org/10.1016/ j.clinbiomech.2013.07.005.

Peirce, S.M., Skalak, T.C., Rodeheaver, G.T., 2000. Ischemia-reperfusion injury in chronic pressure ulcer formation: a skin model in the rat. Wound Repair Regen. Off. Publ. Wound Heal. Soc. Eur. Tissue Repair Soc. 8, 68-76.

Reswick, J.B., Rogers, J.E., 1976. Experience at rancho los amigos hospital with devices and techniques to prevent pressure sores. In: Bed Sore Biomechanics, Strathclyde Bioengineering Seminars. Palgrave, London, pp. 301-310. https://doi.org/10.1007/978-1-349-02492-6_38.

Sae-Sia, W., Wipke-Tevis, D.D., Williams, D.A., 2005. Elevated sacral skin temperature (Ts): a risk factor for pressure ulcer development in hospitalized neurologically impaired Thai patients. Appl. Nurs. Res. 18, 29-35. https://doi. org/10.1016/j.apnr.2004.03.005.

Simo, J.C., Taylor, R.L., 1991. Quasi-incompressible finite elasticity in principal stretches. Continuum basis and numerical algorithms* Juan C. SIMO.

Solis, L.R., Liggins, A., Seres, P., Uwiera, R.R.E., Poppe, N., Pehowich, E., Thompson, R. B., Mushahwar, V.K., 2012. Distribution of internal strains around bony prominences in pigs. Annals Biomed. Eng. 40, 1721-1739. https://doi.org/ 10.1007/s10439-012-0539-y.

Sonenblum, S.E., Sprigle, S.H., Cathcart, J.M., Winder, R.J., 2015. 3D anatomy and deformation of the seated buttocks. J. Tissue Viability 24, 51-61. https://doi.org/ 10.1016/j.jtv.2015.03.003.

Sopher, R., Nixon, J., Gorecki, C., Gefen, A., 2010. Exposure to internal muscle tissue loads under the ischial tuberosities during sitting is elevated at abnormally high or low body mass indices. J. Biomech. 43, 280-286. https://doi.org/10.1016/j. jbiomech.2009.08.021.

Stekelenburg, A., Strijkers, G.J., Parusel, H., Bader, D.L., Nicolay, K., Oomens, C.W. 2007. Role of ischemia and deformation in the onset of compression-induced deep tissue injury: MRI-based studies in a rat model. J. Appl. Physiol. Bethesda Md 1985 (102), 2002-2011. https://doi.org/10.1152/japplphysiol.01115.2006.

Zeevi, T., Levy, A., Brauner, N., Gefen, A., 2017a. Effects of ambient conditions on the risk of pressure injuries in bedridden patients-multi-physics modelling of microclimate. Int. Wound J. 1-15. https://doi.org/10.1111/iwj.12877.

Zeevi, T., Levy, A., Brauner, N., Gefen, A., 2017b. Effects of ambient conditions on the risk of pressure injuries in bedridden patients-multi-physics modelling of microclimate. Int. Wound J. https://doi.org/10.1111/iwj.12877. 